Research Article

\title{
Experimental Study on Multiple Explosions during the Development and Utilization of Oil Shale Dust
}

\author{
Bo Liu $\left(\mathbb{D}\right.$, Yansong Zhang $\left(\mathbb{D}\right.$, Yuyuan Zhang, Jinshe Chen $\mathbb{D}^{D}$, and Xiangbao Meng $(\mathbb{D}$ \\ College of Mining and Safety Engineering, Shandong University of Science and Technology, Qingdao 266590, China \\ Correspondence should be addressed to Xiangbao Meng; mxb@sdust.edu.cn
}

Received 9 August 2019; Accepted 28 September 2019; Published 24 October 2019

Academic Editor: Vadim V. Silberschmidt

Copyright $\odot 2019$ Bo Liu et al. This is an open access article distributed under the Creative Commons Attribution License, which permits unrestricted use, distribution, and reproduction in any medium, provided the original work is properly cited.

\begin{abstract}
Oil shale is a kind of high-combustion heat mineral; in the process of exploitation, storage, and utilization, oil shale dust has the risk of explosion. The explosion characteristics and flame propagation behavior of oil shale dust are worth studying. The difference between the multiple explosion behaviors of oil shale dust was investigated with the use of a $20 \mathrm{~L}$ explosive spherical tank and a dust MIE experimental device. The explosion characteristics and microstructure changes of the explosive products in multiple explosions were examined. The experimental results show that the maximum explosion pressure $\left(P_{\max }\right)$ dropped, and simultaneously, the minimum ignition energy (MIE), the explosion time $(t)$, and the maximum rate of pressure rise $\left((\mathrm{d} p / \mathrm{d} t)_{\max }\right)$ increased as the explosions continued. Furthermore, the oil shale continued exploding until the third explosion. Some original oil shale dust (OOSD) and explosive residues were analyzed using a scanning electron microscope (SEM) and Fourier transform infrared (FT-IR) spectrometer. The SEM images of the explosive residues indicate a high fragmentation degree and well-developed pore structure during the entire multiexplosion process. Oxygen-containing functional groups, the aliphatic $\mathrm{C}-\mathrm{H}$ bond, and the aromatic $\mathrm{C}-\mathrm{H}$ bond in oil shale dust all participated in the oil shale dust explosion process.
\end{abstract}

\section{Introduction}

Fossil fuel is the main energy used in modern industry. As an alternative resource of oil, oil shale is more and more widely used in the world. The proven reserves of oil shale in the world are more than 400 billion [1]. Oil shale belongs to unconventional oil and gas resources. It is a kind of sedimentary rock containing heterogeneous solid combustible organic matter in mineral skeleton and having fine schistosome [2,3]. China's oil shale reserves exceed 700 billion tons and are equivalent to nearly 50 billion tons of shale oil, thereby exhibiting a huge, comprehensive development and utilization value. In the process of exploitation, storage, and utilization, oil shale dust has the risk of explosion.

Multiple explosions of oil shale dust refer to the process in which oil shale dust is exploded again after the first explosion until the explosion fails. A secondary explosion and multiple explosions may bring about more severe consequences than a first explosion, as many explosion suppression or fire protection devices may have been destroyed or used up in the first explosion and thus lose their efficacy in the second explosion. Moreover, a lack of knowledge about the explosion times and sites of secondary and multiple explosions can significantly increase any rescue difficulties. Therefore, it is both urgent and necessary to gain a more in-depth knowledge of the characteristics of secondary and multiple explosions.

Eckhoff extensively investigated the explosive hazard of combustible dust. However, to date, oil shale dust has been poorly investigated $[4,5]$. Hamdan's team, who were scholars from Jordan, experimentally investigated the minimum ignition temperatures (MIT) and minimum explosion concentrations (MEC) of oil shale dust particles with different sizes and compared the explosibility of oil shale dust with that of olive fuel dust. In addition, scholars also have a limited knowledge of multiple explosions $[6,7]$. The investigations regarding secondary explosions have a long 
history in western countries, but started relatively late in China. Cybulski is a pioneer in this field and proposed the mechanisms of secondary explosions in both the mine tunnel and laboratory [8]. Liu et al. investigated secondary explosions in China's coal mines and found that the coal dust concentration, coal dust particle diameter, and ignition energy significantly affected secondary explosions [9]. Some scholars have discussed the secondary explosion characteristics of coal dust and other dust and the microscopic analysis of explosive residues [10-13]. According to the related results, the MIE values of saturated hydrocarbons and their derivatives are approximately $0.2 \mathrm{~mJ}$, and the MIE of hydrogen is only $0.019 \mathrm{~mJ}$, while the MIE values of acetylene and carbon disulfide are $0.019 \mathrm{~mJ}$ and $0.009 \mathrm{~mJ}$, respectively. When the energy of the electrostatic spark exceeds the MIE of the surrounding combustible media, an explosion or fire-related disaster is induced. The electrodischarge energy of an insulator with an electrostatic potential of $30 \mathrm{kV}$ can reach up to hundreds of microjoules, which is enough to trigger an explosion of some combustible explosive mixtures $[14,15]$. Therefore, formulating the corresponding rescue and treatment measures in accordance with the characteristics of an explosive accident, particularly the MIE of the explosive material, is a crucial method of preventing the occurrence of secondary accidents.

Having reviewed the extant literature on dust explosions, it can be concluded that scholars have mainly focused on secondary explosions in the explosion venting period, but have rarely conducted experimental simulations on the multiexplosion process of oil shale dust in an initial explosion site and have neglected the variation rules of the explosive's ignition energy in the multiexplosion process. In this study, using the dust MIE experimental device and a $20 \mathrm{~L}$ explosive spherical tank, the evolution laws of the explosion characteristics and ignition energy of oil shale dust and the variations of the contents of the main chemical elements in the explosive residues were systematically evaluated. This research can provide insightful references for the prevention of accidents.

\section{The Experimental Methods}

2.1. The Equipment. In accordance with the standard GB/ T16425 and EN14034, this study selected a standard $20 \mathrm{~L}$ explosive spherical tank (Figure 1) as the experimental device for investigating oil shale dust explosions [16]. The experimental device mainly consisted of three parts: the main body, control system, and data acquisition system. Before the experiment began, a certain weight of oil shale dust was placed in the dust container with a volume of $0.6 \mathrm{~L}$, and the $10 \mathrm{~kJ}$ chemical igniter at the center was connected to the igniter fuse, while the explosion container was completely closed. The explosion chamber was vacuumized to $-0.06 \mathrm{MPa}$, and the dispersed gas pressure was set as $2.0 \mathrm{MPa}$. When the magnetic valve between the storage vessel and the testing chamber was automatically opened, air and oil shale dust were injected into the explosion chamber and ignited after a delay of $60 \mathrm{~ms}$. After

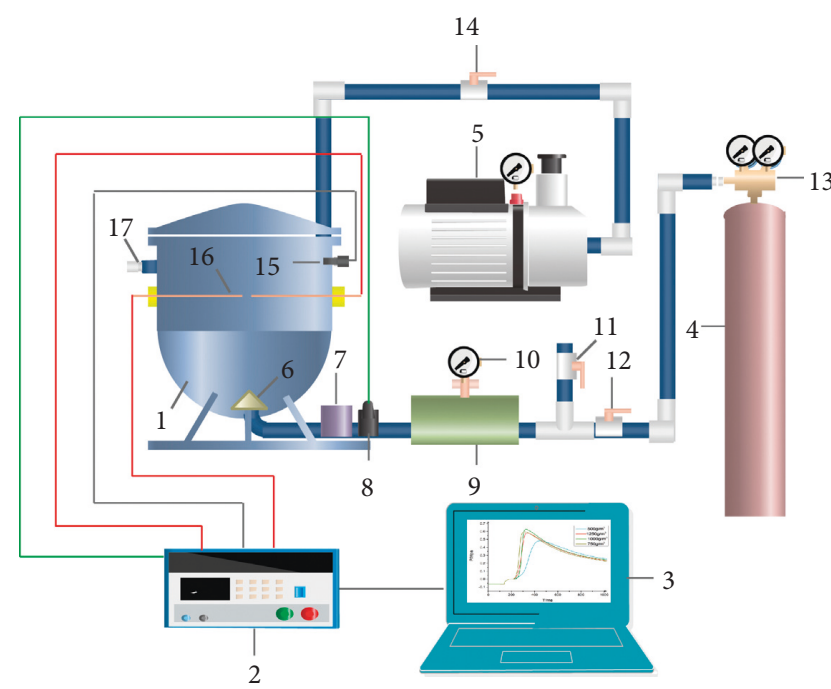

FIgURE 1: The $20 \mathrm{~L}$ explosive spherical tank. (1) $20 \mathrm{~L}$ spherical tank; (2) testing system for explosive characteristics electrode; (3) computer; (4) high-pressure air cylinder; (5) vacuum pump; (6) nozzle; (7) powder storage bin; (8) solenoid valve; (9) highpressure air storage vessel; (10) pressure gauge; (11) exhaust valve 1; (12) air inlet valve; (13) pressure relief valve; (14) vacuum pump ventilation valve; (15) pressure sensor; (16) ignition lead; (17) exhaust valve 2 .

the experiment, the explosion chamber and dust container were thoroughly cleaned using compressed air before the next experiment. During the experiment, the oil shale dust cloud in the container was ignited by the spark igniter based on the principle of zero oxygen balance. The igniter was mainly composed of zirconium $(\mathrm{Zr})$, barium nitrate $\left(\mathrm{Ba}\left(\mathrm{NO}_{3}\right)_{2}\right)$, and barium peroxide $\left(\mathrm{BaO}_{2}\right)$ at a weight proportion of $4: 3: 3.10 \mathrm{~kJ}$ of energy was released from the $2.4 \mathrm{~g}$ chemical igniter.

In this study, at least three experiments were performed on oil shale dust explosions in a standard $20 \mathrm{~L}$ explosive spherical tank to ensure data reliability. The change of explosion pressure was measured by a pressure sensor (manufactured by Yom Electronic Technology Corporation, China) on the container's wall, and the data were recorded by the data acquisition system. Based on the measured data, the timevarying curves of the maximum explosion pressure $\left(P_{\max }\right)$ and maximum pressure rising rate $(\mathrm{d} p / \mathrm{d} t)_{\max }$ were plotted.

With regard to the measurement of the MIE of oil shale dust, the testing device of the dust cloud's MIE recommended by the Verein Deutscher Ingenieur (VDI 2263) and International Electrotechnical Commission (IEC), namely, the HY16428A dust MIE experimental device (1.2 L Hartmann tube), was used in this study. As shown in Figure 2, the experimental device mainly consisted of a quartz glass tube, ignition electrode, and dust spraying system.

A quartz glass tube with a volume of $1.2 \mathrm{~L}$ on the top of the device was used for dust combustion and observing the dust ignition. An umbellate diffuser was arranged in the lower part of the device and used for dust diffusion. During the experiment, the dust particles were uniformly scattered 


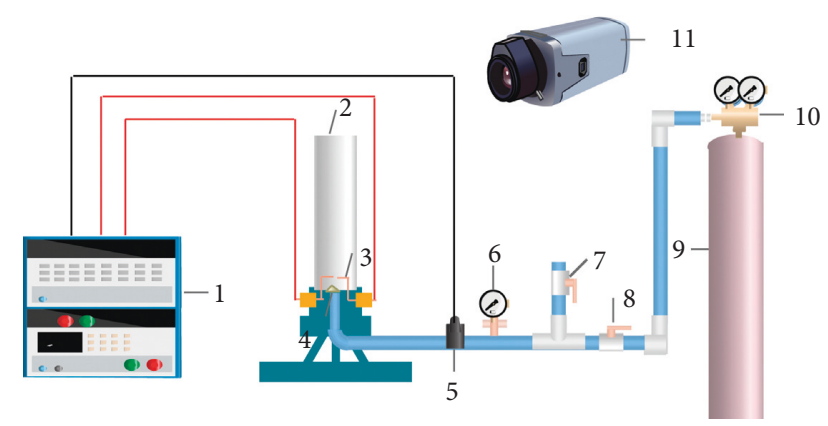

FIgURE 2: Dust MIE experimental device. (1) Ignition energy production system; (2) $1.2 \mathrm{~L}$ glass tube; (3) ignition lead; (4) nozzle, high-pressure air cylinder; (5) powder storage bin; (6) pressure gauge; (7) exhaust valve; (8) air inlet valve; (9) high-pressure air cylinder; (10) pressure relief valve; (11) high-speed camera.

on the bottom of the Hartmann tube and around the umbellate diffuser. Next, the compressed air was forced into the air storage tank via the air inlet unit, and the magnetic valve was opened for dispersing the dust particles into the Hartmann tube, using compressed air, so as to form a dust cloud. Finally, the electrode was ignited for measuring the MIE. The ignition electrode was located on the vertically symmetric axis of the Hartmann tube and approximately $6 \mathrm{~cm}$ above the tube's bottom. Minimum ignition energy is the minimum spark energy that can ignite dust and maintain combustion. In the experiment, if the dust is ignited and the flame propagates at least $60 \mathrm{~mm}$ away from the spark position, it is considered that the dust is ignited, and otherwise, it is considered that the dust is not ignited. The measured MIE $E_{\min }$ ranged from the maximum energy, where the dust failed to catch fire 20 times consecutively $\left(E_{1}\right)$, to the minimum energy, where the dust caught fire 20 times consecutively $\left(E_{2}\right)$, i.e., $E_{1}<E_{\min }<E_{2}$.

2.2. Pretreatment and Testing of Oil Shale Dust. Oil shale dust has a more complex chemical structure and more volatile matter than metal dust. The chemical structure and volatile matter of oil shale dust have always been the focus of the studies regarding explosion parameters and mechanisms [17]. Using the Tyler standard screen, the oil shale dust particles from Longkou City, Shandong Province, China, were ground and sieved in order to obtain oil shale dust with a particle size of under $75 \mu \mathrm{m}$. During the experiment, we dried coal samples for $2 \mathrm{~h}$ in a dryer under $50^{\circ} \mathrm{C}$ to remove the moisture. In order to select an appropriate explosion concentration, the concentration of oil shale dust with a particle size of under $75 \mu \mathrm{m}$ in a $20 \mathrm{~L}$ explosive spherical tank was measured (Figure 3). Figure 3 displays the variation curves of typical pressures in the explosion tests of oil shale dust with time, in which the $P_{\max }$ and $(\mathrm{d} p / \mathrm{d} t)_{\max }$ were measured at certain dust concentrations. The ambient temperature during the experiment was $25^{\circ} \mathrm{C}$, and the relative humidity was $38 \%$. At an explosion concentration of $1000 \mathrm{~g} / \mathrm{m}^{3}$, the maximum explosion pressure was $0.625 \mathrm{MPa}$ and the rising rate of the explosion pressure was $28.36 \mathrm{MPa} / \mathrm{s}$.

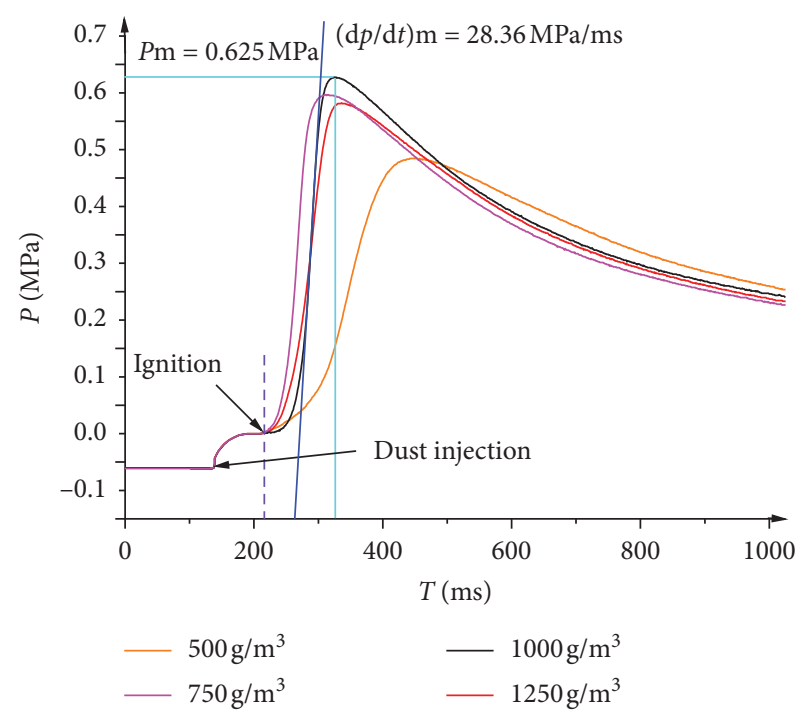

FIgURE 3: The explosion curves of oil shale dust at different concentrations.

The dust concentration with the maximum explosion pressure is used as the experimental concentration, which can make the experimental data more representative. So, the explosion concentration was set as $1000 \mathrm{~g} / \mathrm{m}^{3}$ for further analysis.

For conducting simulations on multiple explosions in the initial explosion region and differentiating the above processes, the first explosion of the OOSD was simulated in the $20 \mathrm{~L}$ explosive spherical tank; after the first explosion, the first explosive residue (FER) was collected for the second explosion experiment. Next, the second explosive residue (SER) was collected for the third explosion experiment, and the third explosive residue (TER) was collected for the fourth explosion experiment until the dust sample did not explode. Using the $P_{\max }, t$, and $(\mathrm{d} p / \mathrm{d} t)_{\max }$ of oil shale dust as the main explosion parameters, the first $\mathrm{N}$ explosions of oil shale dust were compared.

Using the dust MIE experimental device, the MIE values of unexploded dust and the dust residues in the first $\mathrm{N}$ explosions were measured.

\section{Results and Discussion}

3.1. An Analysis of the Experimental Results in the 20 L Explosive Spherical Tank. The explosion characteristics of oil shale dust with a particle size of under $75 \mu \mathrm{m}$ were examined in a $20 \mathrm{~L}$ explosive spherical tank, during which the concentration of oil shale dust and ignition energy was set as $1000 \mathrm{~g} / \mathrm{m}^{3}$ and $10 \mathrm{~kJ}$, respectively. The residues after each explosion were collected for the next explosion experiment under the same conditions. The results show that, after three explosions, the residue of oil shale dust underwent no explosion. Figure 4 displays the evolutionary curves of typical oil shale dust overpressures during the first three explosions in the $20 \mathrm{~L}$ explosive spherical tank.

As shown in Figure 4, the main dust explosion parameters $\left(P_{\max }, t\right.$, and $\left.(\mathrm{d} p / \mathrm{d} t)_{\max }\right)$ differed greatly in the first 


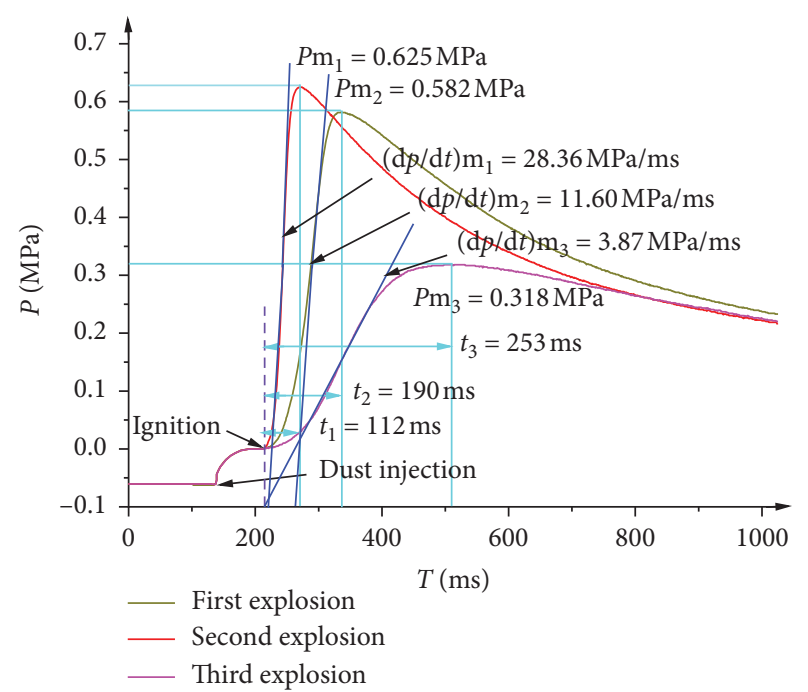

FIGURE 4: The evolutionary curves of the explosion overpressures in the first three explosions.

three explosions. The value of $P_{\max }$ in the first explosion was $0.625 \mathrm{MPa}$, which exceeded that in the second explosion by $0.043 \mathrm{MPa}$. The value of $P_{\max }$ in the second explosion was $0.266 \mathrm{MPa}$ greater than that in the third explosion. The value of $t$ in the first explosion was $60.7 \%$ smaller than that in the second explosion, while the value of $t$ in the second explosion was $33.1 \%$ smaller than that in the third explosion. During the explosion process, the $P_{\max }$ dropped gradually, and simultaneously, $t$ and $(\mathrm{d} p / \mathrm{d} t)_{\max }$ increased steadily [18]. The difference in $P_{\max }$ can be mainly attributed to different volatile components. Table 1 lists the industrial analysis results of the solid residues. $7.40 \%$ of volatiles were consumed in the first explosion, which was 2.76 and 1.71 times greater than those consumed in the second and third explosions, respectively. Previous results $[19,20]$ also indicated that the volatile matter was the most important variable affecting the value of $P_{\max }$ of the explosive dust, which fits well with the findings of this study.

Figure 5 compares the industrial analysis data of the explosive residues of oil shale dust after multiple explosions, from which we can observe significant differences of the explosibility of oil shale dust particles after multiple explosions. In addition to the reduction of volatile materials, the increase of the ash content and the decline in the fixed carbon content are also important factors that resulted in the differences in the explosibility. It is noteworthy that the consumption of fixed carbon in the second explosion was $13.10 \%$ higher than that in the first explosion, and the consumption of fixed carbon in the third explosion was $10.4 \%$ higher than that in the second explosion. When there was a low volatile matter content, the gasification weakened, the combustion of the heterogeneous phase was enhanced, and the consumption of fixed carbon increased slightly. The influence of standard dust diffuser on dust particle size is also a key factor that can not be ignored when analyzing the difference of multiple explosion parameters. Current research results show that the combination of outlet valve and diffusive nozzle may cause abrasion and impact on oil
TABle 1: Industrial analysis of oil shale dust.

\begin{tabular}{lcccc}
\hline \multirow{2}{*}{ Oil shale dust } & \multicolumn{4}{c}{ Proximate analysis (\% by mass) } \\
& Moisture & Ash & Volatile matter & Fixed carbon \\
\hline OOSD & 0.57 & 39.37 & 39.49 & 17.75 \\
FER & 0.55 & 48.60 & 36.56 & 12.24 \\
SER & 0.54 & 56.71 & 26.56 & 10.60 \\
TER & 0.54 & 60.33 & 20.13 & 9.15 \\
\hline
\end{tabular}

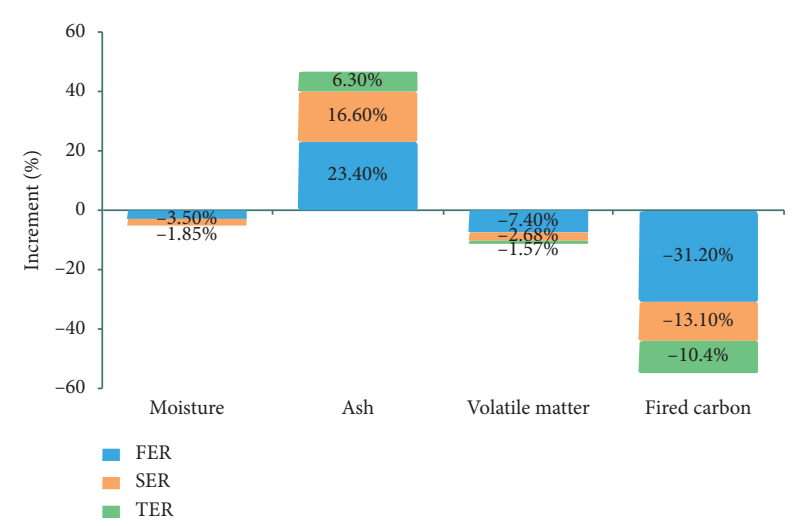

FIgURE 5: A comparison of the industrial analysis results of the explosive residues of oil shale dust after multiple explosions.

shale dust particles, which will lead to the reduction of oil shale dust particle size [21]. In order to reduce the differences, crude oil shale dust was collected after the dust spraying. Because of the damage to the oil shale structure in the combustion process, the dust particles after an explosion were more easily damaged than the original dust particles, and therefore, the diffuser was better at capturing the dust particles after an explosion. Therefore, the actual difference between the explosion parameters in multiple explosions may be greater than those revealed in the experimental data.

\subsection{An Analysis of the Experimental Results in the Dust MIE} Experimental Device. The oil shale dust particles after the explosion in the $20 \mathrm{~L}$ explosive spherical tank were collected for the measurement of the MIE in the dust MIE experimental device. The quality of oil shale dust put into the dust MIE experimental device is equal to $1 \mathrm{~g}$ each time. The MIE values of the OOSD, FER, SER, and TER were measured, and therefore, the variation curves of the MIE of oil shale dust after multiple explosions and the related fitted curves were plotted. Figure 6 displays the entire explosion process of oil shale dust and the variation of the MIE. The MIE values of the OOSD, FER, and SER were $40 \mathrm{~mJ}, 60 \mathrm{~mJ}$, and $130 \mathrm{~mJ}$, respectively, and the TER did not explode. The MIE value of FER was 2.5 times greater than that of the OOSD. The explosion flame weakened as the oil shale dust explosions continued.

Figure 7 displays the industrial analysis results of oil shale dust before and after the explosions and the variation tendency of the MIE. As the explosions continued, the 


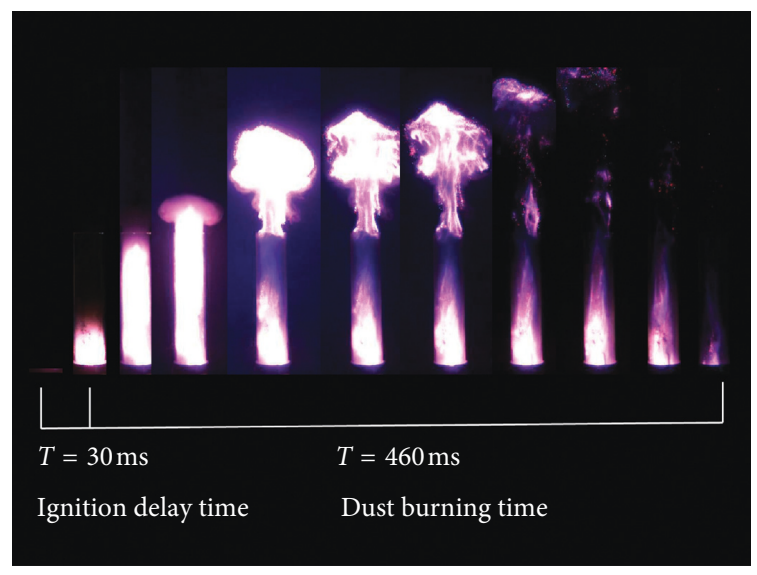

(a)

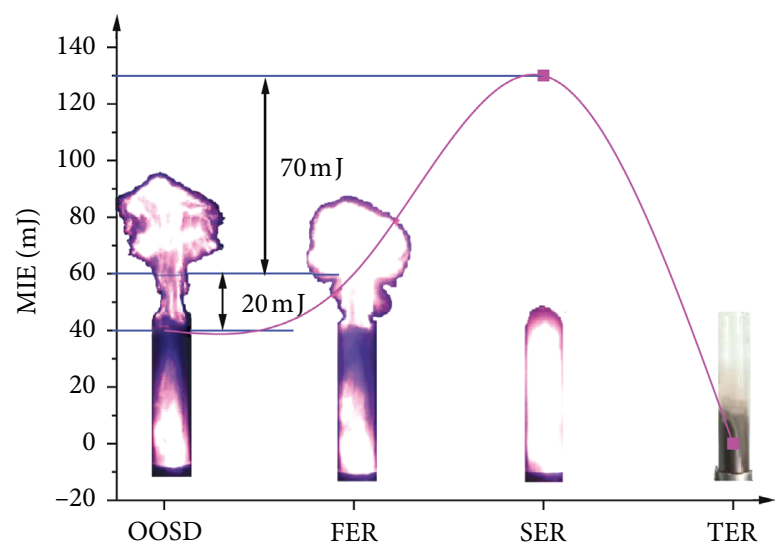

(b)

FIgURE 6: The experimental process of the explosion of oil shale dust and an analysis of the MIE: (a) the experimental process of the measurement of the MIE of oil shale dust and (b) the variation curve of the MIE of oil shale dust in the multiexplosion process.

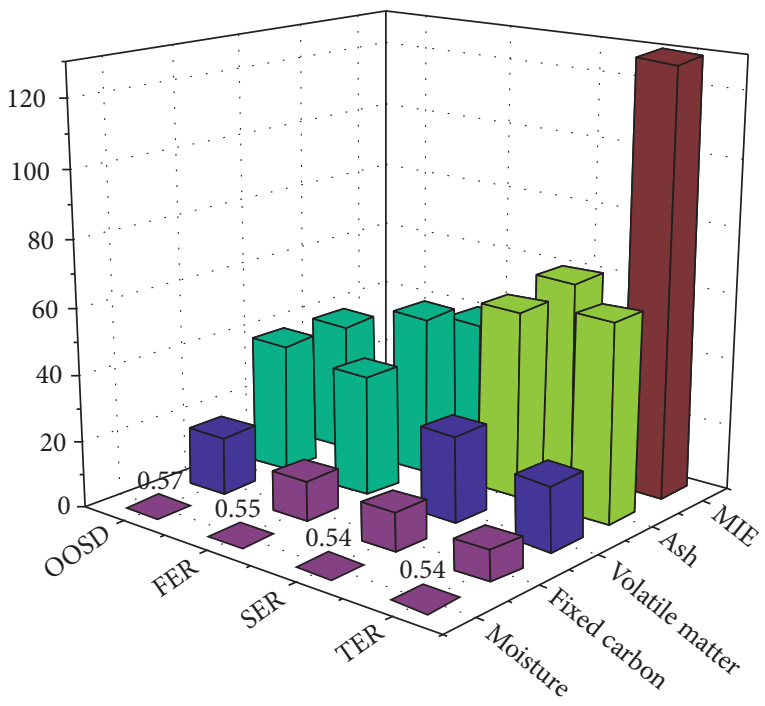

FIgURE 7: The industrial analysis results of oil shale dust and the variation tendency of the MIE.

moisture content, the fixed carbon content, and the volatile matter content dropped gradually and were negatively correlated with the MIE, and simultaneously, the ash content and the MIE value increased gradually, both of which exhibited a positive correlation. In combination with the analysis results in Figure 5, the rapid increase of the ash content and drastic decrease of the volatile matter content in the second explosion led to the rapid increase of the MIE.

\subsection{The Microanalysis Results of Multiple Explosions of Oil} Shale Dust. Figure 8 displays the images of the OOSD and dust particles after three explosions under the SEM. A lot of unburnt particles remained in the dust after the first explosion, suggesting a low combustion degree, while the particles increased in volume and aggregated. After the second explosion, the dust particles were heavily fractured and a pore structure developed. After the third explosion, the number of unburnt particles was reduced, the dust particles involved in the reaction exhibited a more developed pore structure, and some cavities even appeared.

\subsection{An Analysis of the Infrared (IR) Spectra of Oil Shale Dust} Samples before and after the Explosion. Fourier transform infrared spectroscopy (FT-IR) is an effective way of investigating the chemical structure of coal or oil shale. The IR spectra of the OOSD, FER, SER, and TER can clearly reflect the variation tendency of the functional groups in oil shale dust and the related structural change.

Using the FT-IR spectrometer (VERTEX 70, Bruker, Germany), the types and relative contents of the functional groups in oil shale dust and the residues were examined. Figure 9 displays the FT-IR spectra of oil shale dust and the residues in the range of $400-4000 \mathrm{~cm}^{-1}$.

Song Lin et al. analyzed coal dust explosive residues by infrared spectroscopy. In this paper, similar methods were used to study oil shale explosive residues [22, 23]. The functional groups of oil shale in different wave ranges and the chemical structures were also examined. Table 2 lists the vibration peaks in the different bands and the corresponding functional groups or chemical bonds as shown in Figure 9 .

Before explosion, the chemical structure vibration peaks of oil shale dust samples were mainly between 700 and $900 \mathrm{~cm}^{-1}, 1000$ and $1700 \mathrm{~cm}^{-1}, 2800$ and $3200 \mathrm{~cm}^{-1}$, and 3300 and $3600 \mathrm{~cm}^{-1}$. The functional groups mainly contain aliphatic $\mathrm{C}-\mathrm{H}$ bonds, aromatic $\mathrm{C}-\mathrm{H}$ bonds, and hydroxyl groups, ethers, carbonyls, and so on.

Compared with the FT-IR spectra of the dust sample before the explosion, the intensity of various vibration peaks corresponding to the chemical structures in the dust sample after the explosion dropped significantly. With the increasing number of explosions, the intensity of the vibration peaks corresponding to the chemical structures became 

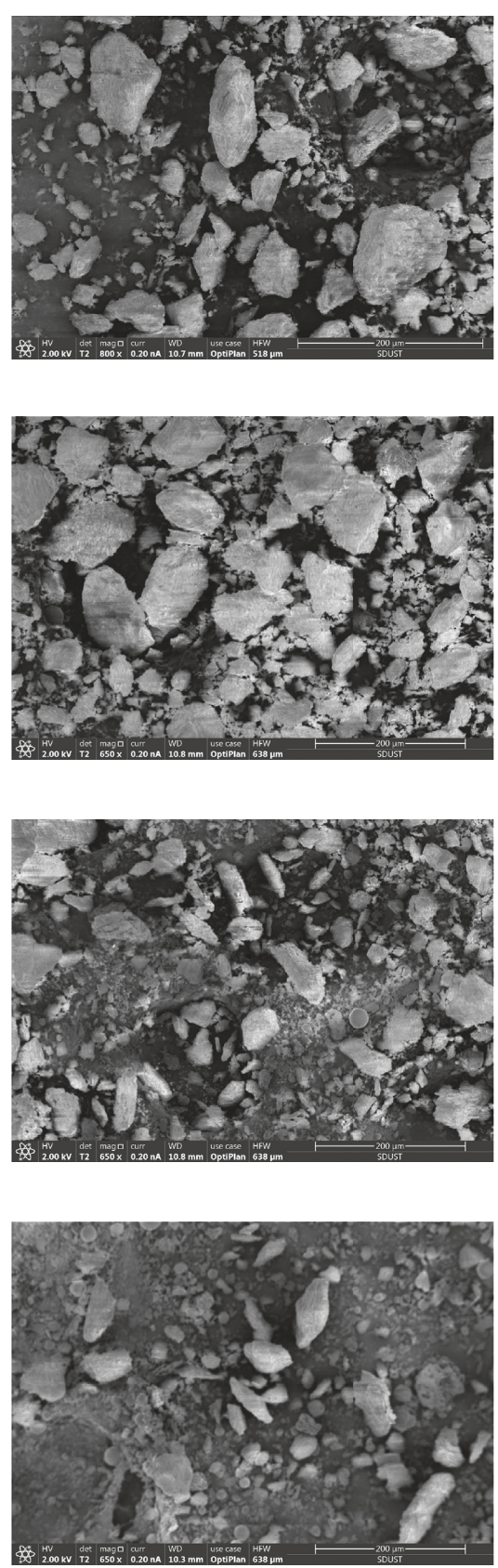

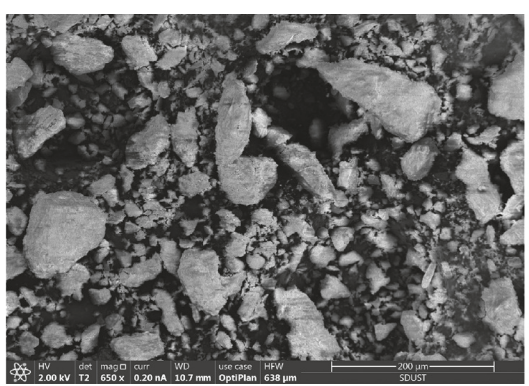

(a)

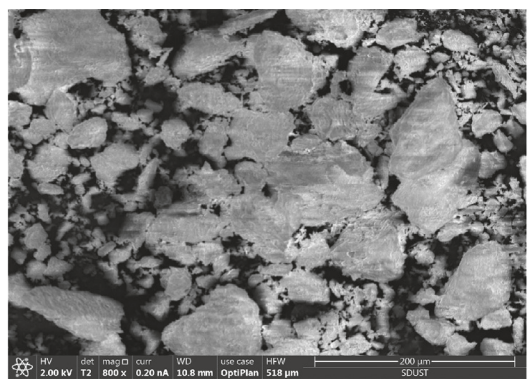

(b)

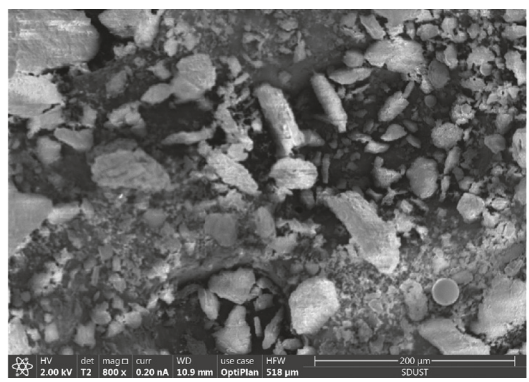

(c)

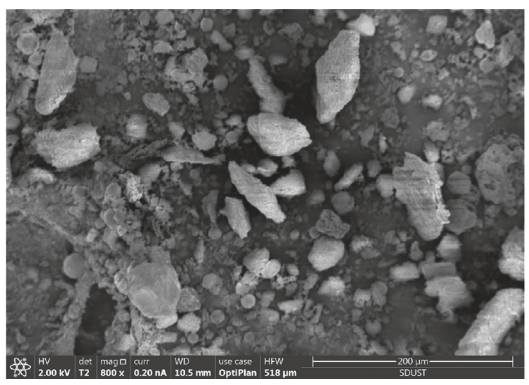

(d)
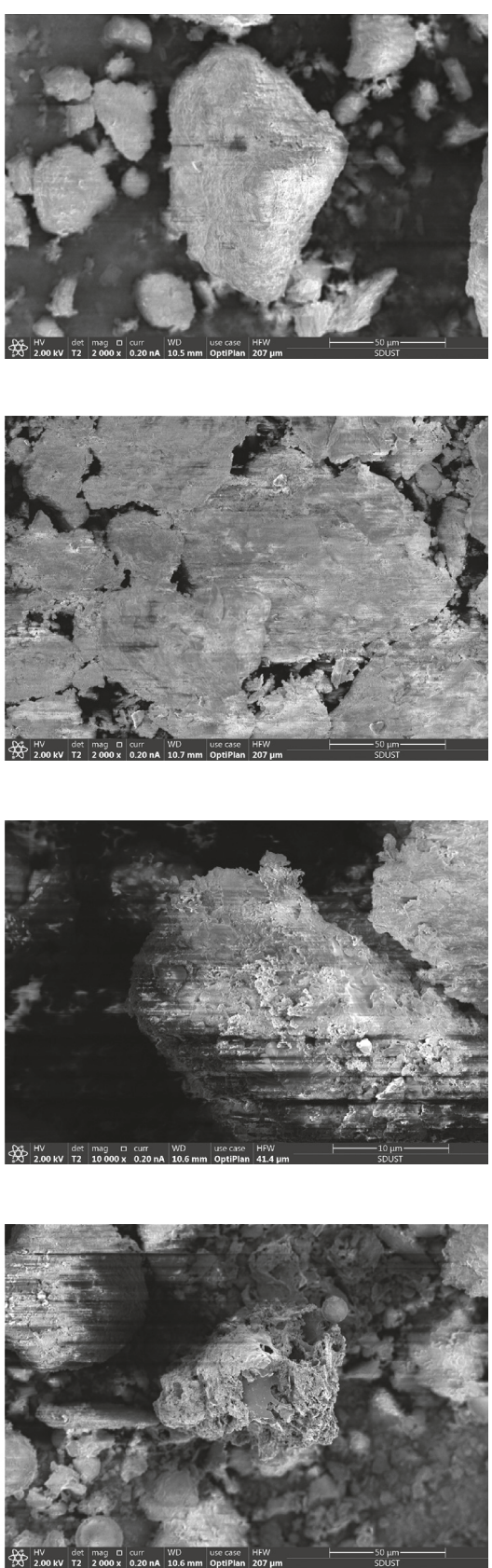

FIgURE 8: The SEM images of oil shale dust particles: (a) OOSD; (b) FER; (c) SER; (d) TER.

weaker, and some vibration peaks even disappeared (as described in the FT-IR spectra of the TER). According to the measured FT-IR spectra, the vibration peak of hydroxyl at $3546 \mathrm{~cm}^{-1}$, the vibration peaks of the aliphatic series at 2988 $\mathrm{cm}^{-1}$ and $2848 \mathrm{~cm}^{-1}$, and the vibration peak of carbonyl at $2120 \mathrm{~cm}^{-1}$ disappeared, and the vibration peak of hydroxyl at $3237 \mathrm{~cm}^{-1}$, the vibration peaks of the aromatic skeletons at $1637 \mathrm{~cm}^{-1}$ and $1488 \mathrm{~cm}^{-1}$, and the vibration peaks of the oxygen-containing functional groups at $1167 \mathrm{~cm}^{-1}$ and $1003 \mathrm{~cm}^{-1}$ weakened. The enhancement of the vibration peak at $621 \mathrm{~cm}^{-1}$ suggests an increase of the minerals and ash content in the explosive residues.
The above results also demonstrate that a lot of chemical structures including the aliphatic $\mathrm{C}-\mathrm{H}$ bond, aromatic $\mathrm{C}-\mathrm{H}$ bond, and some oxygen-containing functional groups were involved in the explosion process of oil shale dust.

\section{Conclusions}

In the $20 \mathrm{~L}$ explosive spherical tank, the oil shale dust underwent three explosions and the third explosive residue did not explode. As the explosions continued, the $P_{\max }$ dropped gradually, while the values of $t$ and $(\mathrm{d} p / \mathrm{d} t)_{\max }$ increased steadily. The MIE values of the collected dust sample were 


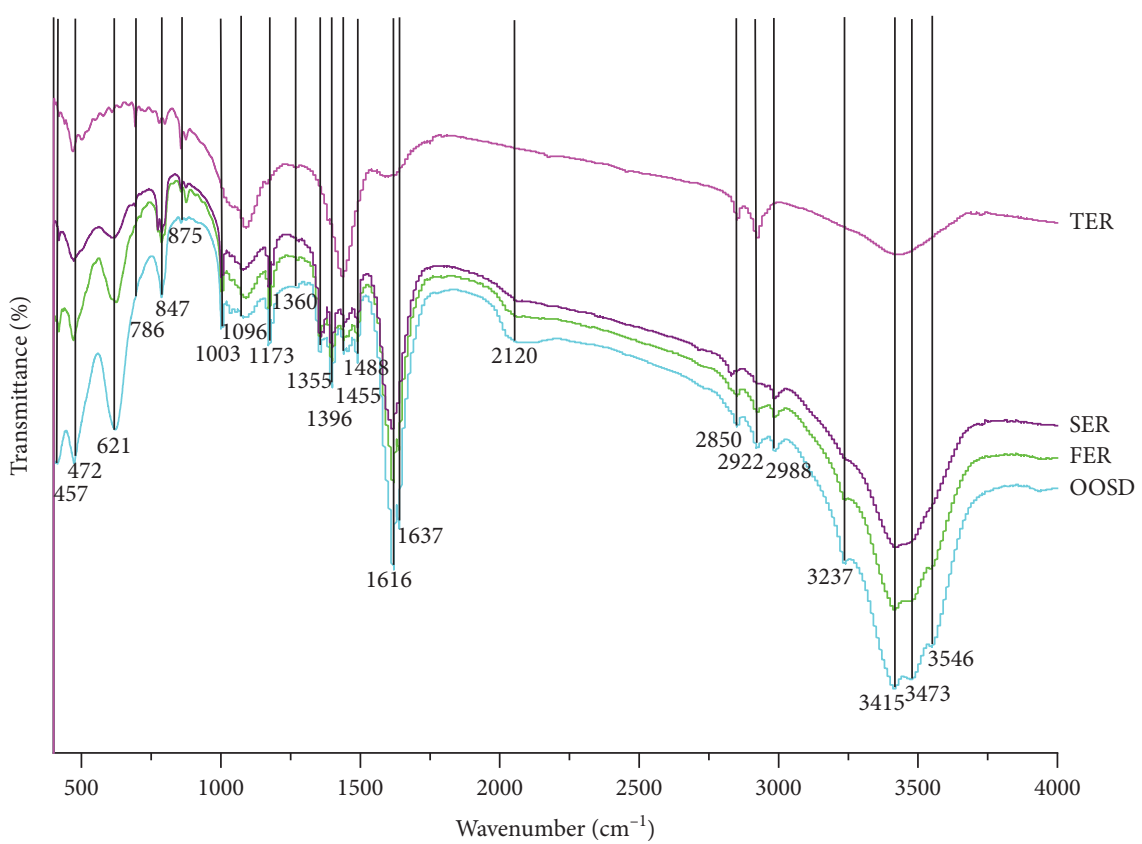

Figure 9: The FT-IR spectra of oil shale dust before and after an explosion.

TABLE 2: Chemical structure in oil shale.

\begin{tabular}{|c|c|c|}
\hline $\begin{array}{l}\text { Sequence } \\
\text { number }\end{array}$ & $\begin{array}{l}\text { Wavenumber } \\
\qquad\left(\mathrm{cm}^{-1}\right)\end{array}$ & $\begin{array}{l}\text { Vibration peak and the } \\
\text { corresponding structure }\end{array}$ \\
\hline 1 & 3546,3237 & $-\mathrm{OH}$ stretching \\
\hline 2 & 2988,2848 & Aliphatic C-H stretching \\
\hline 3 & 2120 & Carbonyl stretching \\
\hline 4 & 1637,1488 & Aromatic ring stretching \\
\hline 5 & 1397 & Aliphatic $-\mathrm{CH}_{3}$ deformation \\
\hline 6 & 1167 & Ether \\
\hline 7 & 1003 & $\begin{array}{l}\text { Aliphatic ether C-O-and alcohol } \\
\text { C-O- stretching }\end{array}$ \\
\hline 8 & $875,847,766$ & $\begin{array}{c}\text { Aromatic C-H out-of-plane } \\
\text { deformation }\end{array}$ \\
\hline 9 & 621,457 & $\begin{array}{l}\text { Calcium carbonate, phosphate, } \\
\text { and sulfate groups }\end{array}$ \\
\hline
\end{tabular}

measured in a dust MIE experimental device. The measured MIE values of the original oil shale dust, the first explosive residue, and the second explosive residue were $40 \mathrm{~mJ}$, $60 \mathrm{~mJ}$, and $130 \mathrm{~mJ}$, respectively, and the third explosive residue did not explode. With the development of explosion, the ignition energy required for explosion of explosive residues increases. In combination with the industrial analysis results, the sharp increase of ash and the sharp decrease of volatile matter are the reasons for the sharp rise of MIE.

SEM analysis shows that, with the explosion proceeding, the pore structure of dust particles participating in the reaction becomes more and more developed. According to the FT-IR spectra, the chemical structures of oil shale dust played important roles in the oil shale dust explosion process, which dropped significantly after the explosion. The enhancement of the vibration peak at $621 \mathrm{~cm}^{-1}$ suggested that a part of the reactants was transformed into ash.

\section{Data Availability}

The data used to support the findings of this study are available from the corresponding author upon request.

\section{Conflicts of Interest}

The authors declare that there are no conflicts of interest regarding the publication of this paper.

\section{Acknowledgments}

This research was funded by the Key Research and Development Project of Shandong Province (2018GSF120016 and 2018GGX109004), the National Key Research and Development Plan (2017YFC0805200 and 2016YFC0801700), and the China Postdoctoral Science Foundation (2018M632693).

\section{References}

[1] H. Liu, B. Yu, J. Liu, and T. Wang, "Investigation of impact rock burst induced by energy released from hard rock fractures," Arabian Journal of Geosciences, vol. 12, no. 12, p. 381, 2019.

[2] J. Wang, X. Meng, X. Ma, Q. Xiao, B. Liu, and G. Zhang, "Experimental study on whether and how particle size affects the flame propagation and explosibility of oil shale dust," Process Safety Progress, vol. 38, no. 3, Article ID e12075, 2019.

[3] W. Du, G. Wang, Y. Wang, and X. Liu, "Thermal degradation of bituminous coal with both model-free and model-fitting methods," Applied Thermal Engineering, vol. 152, pp. 169-174, 2019.

[4] R. K. Eckhoff, "Dust explosions in the process industries," Fire Safety Journal, vol. 30, no. 4, p. 397, 1998.

[5] F. K. Sweis, "The effect of admixed material on the ignition temperature of dust layers in hot environments1. This work 
was carried out during sabbatical leave from the University of Jordan.1," Journal of Hazardous Materials, vol. 63, no. 1, pp. 25-35, 1998.

[6] M. A. Hamdan and A. Qubbaj, "Inhibition effect of inert compounds on oil shale dust explosion," Applied Thermal Engineering, vol. 18, no. 5, pp. 221-229, 1998.

[7] M. A. Hamdan and A. Sakhrieh, "Dust explosion of oil shale and olive cake solid fuels: a comparison study," International Journal of Energy Research, vol. 29, no. 10, pp. 871-878, 2005.

[8] W. G. Cybulski, Coal Dust Explosions and Their Suppression, Polish. NTIS No. TT 73-54001, Warsaw, Poland, 1975.

[9] H. X. Liu, Z. T. Liu, J. F. Qian, S. Hong, L. M. Qiu, and R. Zhang, "Research on secondary explosion characteristic of coal dust," Industry and Mine Automation, vol. 44, pp. 80-85, 2018.

[10] Y. Xingqing, L. Di, and Y. Jianliang, "Secondary explosions in relief duct during aluminum dust explosion venting," Procedia Engineering, vol. 45, pp. 431-434, 2012.

[11] Y. Zhang, F. Jiao, Q. Huang et al., "Experimental and numerical studies on the closed and vented explosion behaviors of premixed methane-hydrogen/air mixtures," Applied Thermal Engineering, vol. 159, Article ID 113907, 2019.

[12] P. Zhang, Y. Du, S. Wu, Y. Zhou, J. Zhou, and J. Xu, "Experiments of the secondary ignition of gasoline-air mixture in a confined tunnel," Journal of Thermal Analysis and Calorimetry, vol. 118, no. 3, pp. 1773-1780, 2014.

[13] Y. Zhang, W. Cao, G. Rao, L. Liu, H. Zhou, and Y. Tan, "Experiment-based investigations on the variation laws of functional groups on ignition energy of coal dusts," Combustion Science and Technology, vol. 190, no. 10, pp. 18501860, 2018.

[14] W. Cao, Q. Qin, W. Cao et al., "Experimental and numerical studies on the explosion severities of coal dust/air mixtures in a 20-L spherical vessel," Powder Technology, vol. 310, pp. 17-23, 2017.

[15] B. M. Wiechula, "The incendivity hazards of electrostatic discharges from charged, non-conductive solid materials," Fire Safety Journal, vol. 60, pp. 46-55, 2013.

[16] S. Hong, Z. T. Liu, E. L. Zhao et al., "Comparison of behavior and microscopic characteristics of first and secondary explosions of coal dust," Journal of Loss Prevention in the Process Industries, vol. 49, pp. 382-394, 2017.

[17] Z. Liu, S. Lin, S. Zhang, E. Wang, and G. Liu, "Observations of microscopic characteristics of post-explosion coal dust samples," Journal of Loss Prevention in the Process Industries, vol. 43, pp. 378-384, 2016.

[18] A. E. Dahoe, J. F. Zevenbergen, S. M. Lemkowitz, and B. Scarlett, "Dust explosions in spherical vessels: the role of flame thickness in the validity of the "cube-root law"," Journal of Loss Prevention in the Process Industries, vol. 9, no. 1, pp. 33-44, 1996.

[19] P. Wang, L.-s. Jiang, P.-q. Zheng, G.-p. Qin, and C. Zhang, "Inducing mode analysis of rock burst in fault-affected zone with a hard-thick stratum occurrence," Environmental Earth Sciences, vol. 78, no. 15, p. 467, 2019.

[20] J. Yuan, W. Wei, W. Huang, B. Du, L. Liu, and J. Zhu, "Experimental investigations on the roles of moisture in coal dust explosion," Journal of the Taiwan Institute of Chemical Engineers, vol. 45, no. 5, pp. 2325-2333, 2014

[21] S. Lin, Z. Liu, J. Qian, and X. Li, "Comparison on the explosivity of coal dust and of its explosion solid residues to assess the severity of re-explosion," Fuel, vol. 251, pp. 438446, 2019.
[22] S. Lin, Z. Liu, E. Zhao et al., "A study on the FTIR spectra of pre- and post-explosion coal dust to evaluate the effect of functional groups on dust explosion," Process Safety and Environmental Protection, vol. 130, pp. 48-56, 2019.

[23] K. E. Washburn and J. E. Birdwell, "Multivariate analysis of ATR-FTIR spectra for assessment of oil shale organic geochemical properties," Organic Geochemistry, vol. 63, pp. 1-7, 2013. 


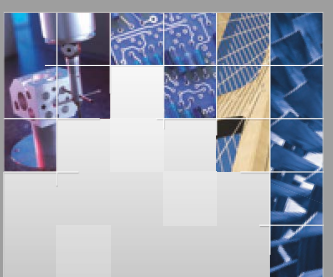

\section{Enfincering}
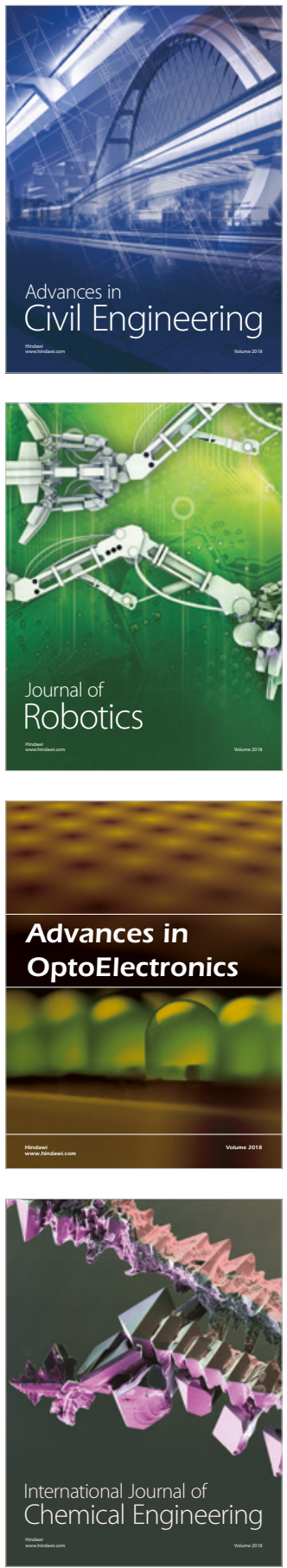

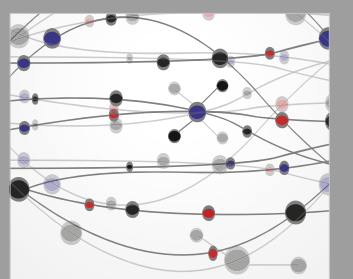

\section{Rotating \\ Machinery}

The Scientific World Journal

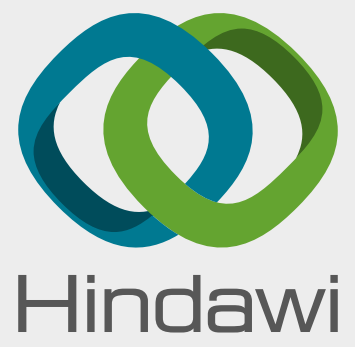

Submit your manuscripts at

www.hindawi.com
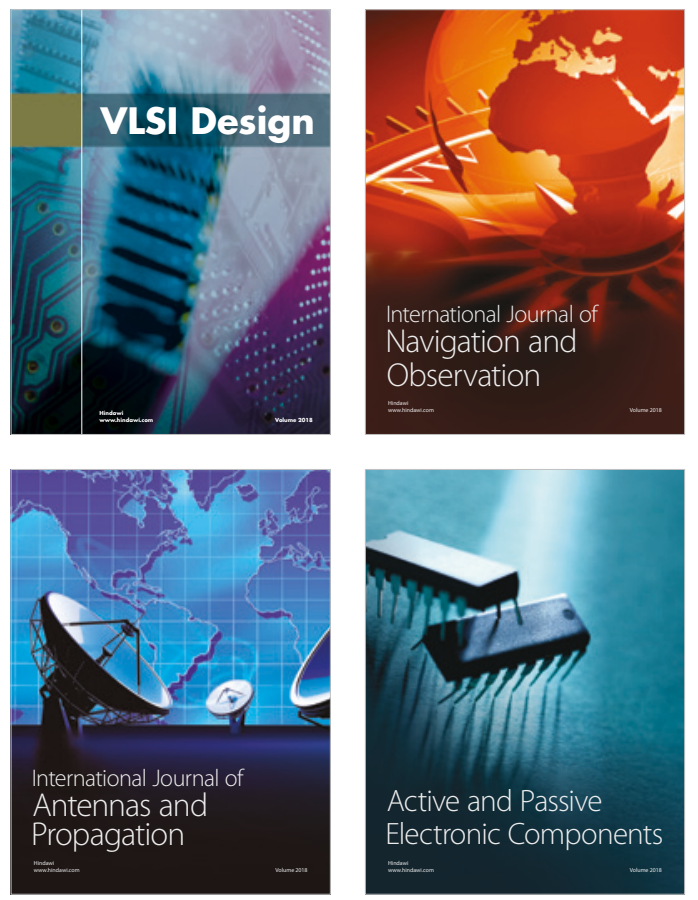
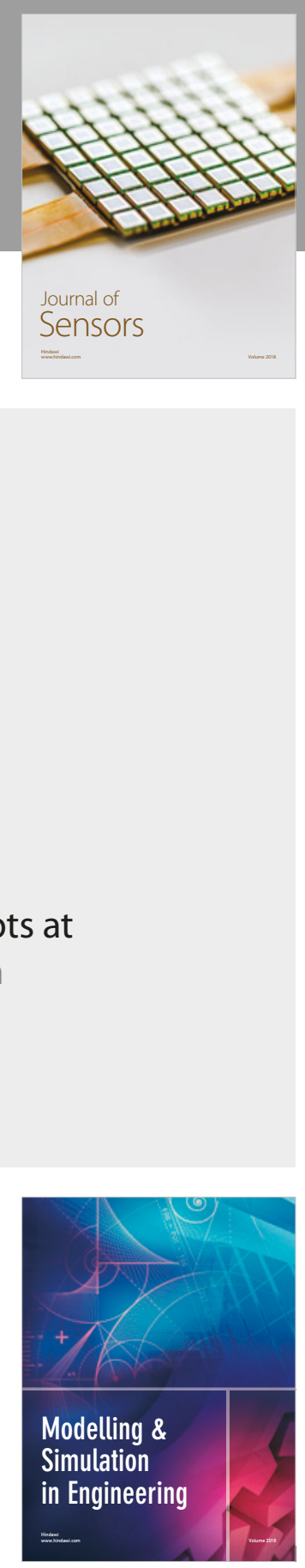

\section{Advances \\ Multimedia}
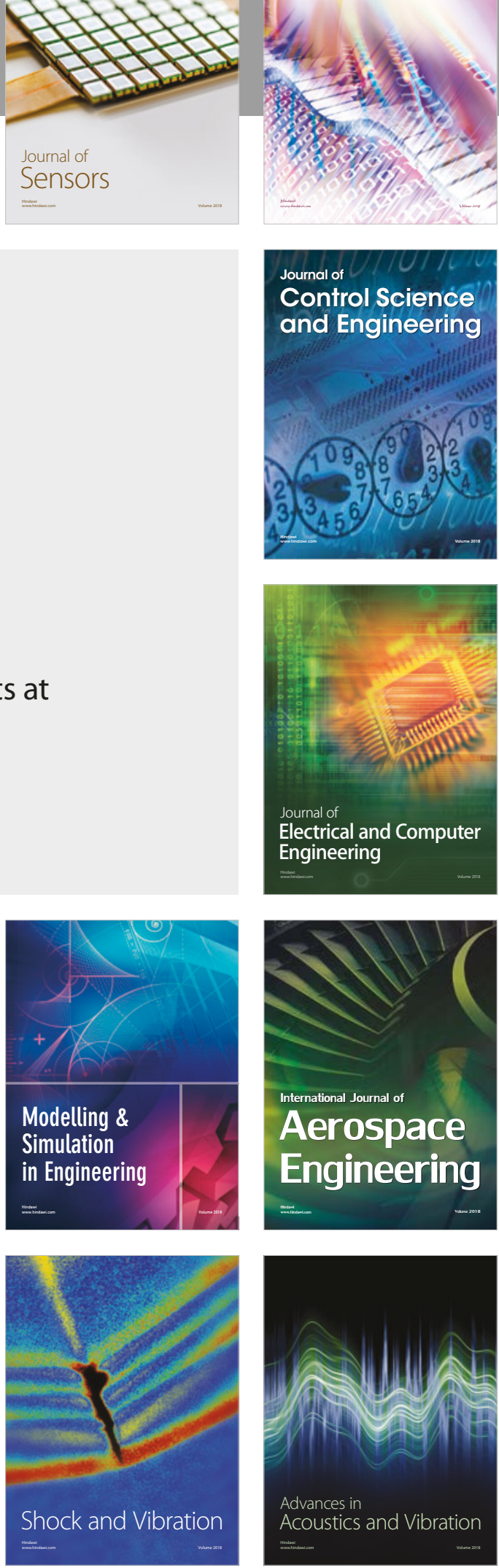